\title{
CHARACTERISATION OF EXSOLUTION PHENOMENA BY MAPPING EELS FINE STRUCTURE
}

Ute Golla-Schindler, Günter Lang, Gerd Benner

LEO Elektronenmikroskopie GmbH, D-73446 Oberkochen, Germany

The aim of obtaining structural and chemical information from increasingly smaller volumes is a driving force in the development of transmission electron microscopes. The new generation of field emission electron microscopes equipped with an energy filter enables excellent spatial as energy resolution and opens an avenue for advanced application like mapping EELS fine structure to e.g. determine valence and bonding states spatially resolved.

The investigated sample is a hematite $\left(\mathrm{Fe}^{3+}{ }_{2} \mathrm{O}_{3}\right)$ - ilmenite $\left(\mathrm{Fe}^{2+} \mathrm{TiO}_{3}\right)$ solid solution, one of the major palaeomagnetic carriers in rocks. The composition and size of fine precipitates resulting from exsolution generated during cooling control the magnetic properties. This system was subject of a number of investigations and there are still unsolved questions about the correlation of microstructure and magnetic properties e.g. self-reversed magnetism found in vulcanic rocks [1]. The TEM specimen was prepared from a polished thin section of a rock and ion beam thinned. The investigations were performed using the SESAMe II, a $200 \mathrm{keV}$ field emission microscope equipped with the new designed $90^{\circ}$ incolumn Omega energy filter [2]. All images were gain and dark count corrected and recorded with an attached $2 \mathrm{~K}$ Gatan slow-scan CCD Camera.

Nowadays fingerprinting techniques are well established for phase analysis. One of the common problems is the accurate calibration of the energy scale to compare the ELNES and determine the energy shift precisely for different phases. Orienting a specimen area, which contains simultaneously both phases parallel to the energy dispersive direction and taking image spectra avoids this problem.

FIG. 1 shows the different scales of exsolution, wide ilmenite rich exsolution lamellae (FIG. 1a) are surrounded by a precipitation free zone and small ilmenite rich precipitates (FIG. 1b,c). In our investigation, the EELS of the element characteristic area (FIG. 2a) and the image spectra of FIG. 2b were collected from the selected specimen area shown in the Ti map (FIG. 1c). The corresponding EELS spectra for the Ti $\mathrm{L}_{23}$-edge result in the same ELNES and energy position for both phases, but the $\mathrm{O} \mathrm{K}$-edge as well as the $\mathrm{Fe}_{23}$-edge show phase-characteristic energy shift and ELNES structures (FIG. 2c). The energy shift and ELNES of the Fe $\mathrm{L}_{23}$-edge can be used to quantify and image the oxidation states for the different exsolved phases [3,4]. Additionally the use of the O K ELNES, which is clearly visible, allows to distinguish between both phases and allow phase mapping as done for the $\mathrm{C} \mathrm{K}$-edge [5]. This ELNES variation of oxygen is due to changes of the density of states and is an extremely sensitive indicator for the bonding or valence state of the atom and will be helpful for the investigation of all processes where no significant changes in chemistry occur (e.g. oxidation) [6].

\section{References}

[1] G.L: Nord and C.A. Lawson, Am Mineral 47 (1989) 160

[2] G. Lang et. al., MM Proc. (2002), this volume

[3] P.A.van Aken et al., Phys. Chem. Miner. 25 (1998) 323.

[4] U. Golla and A. Putnis Phys. Chem. Miner. 28 (2001) 119.

[5] J. Mayer and J.M. Plitzko J. Microsc. 183 (1996) 2.

[6] We thank Dr. S. McEnroe for the samples and Prof. Dr. A. Putnis, Dr. B. Schindler, Dr. A. Orchowski and Dr. W.-D. Rau for their aid. 

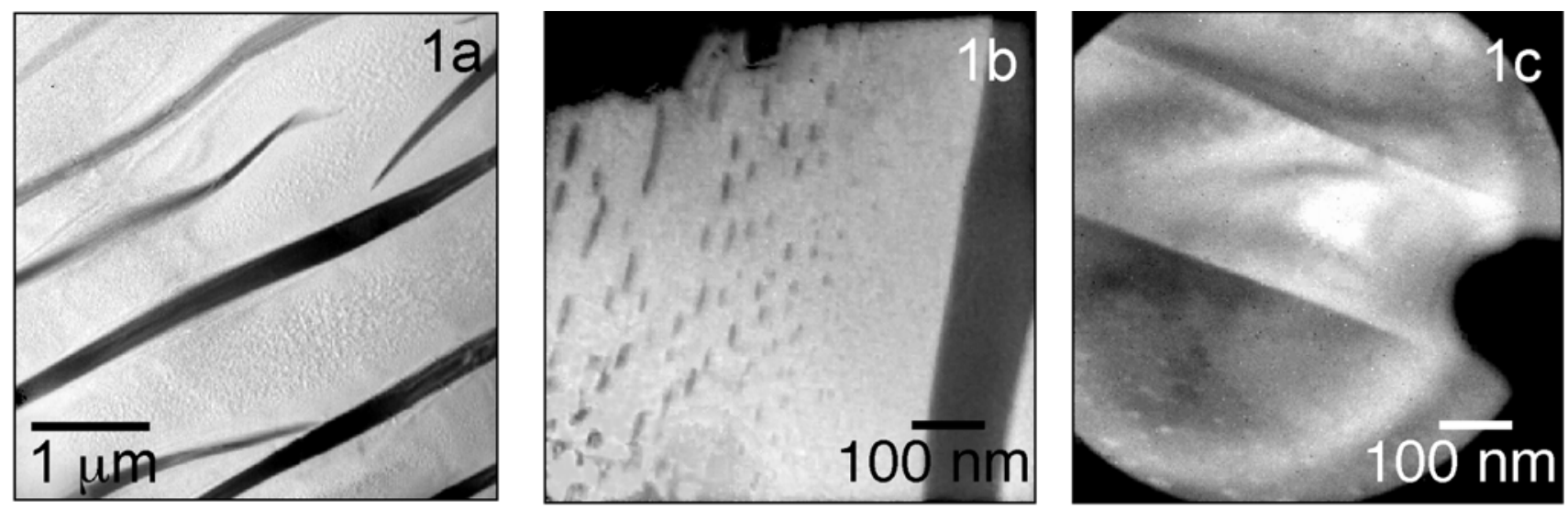

FIG. 1 a-c Element distribution images of titanohematite exsolution lamellae. a,b Fe jump ratio images c Ti map of the selected area for the ELNES investigations
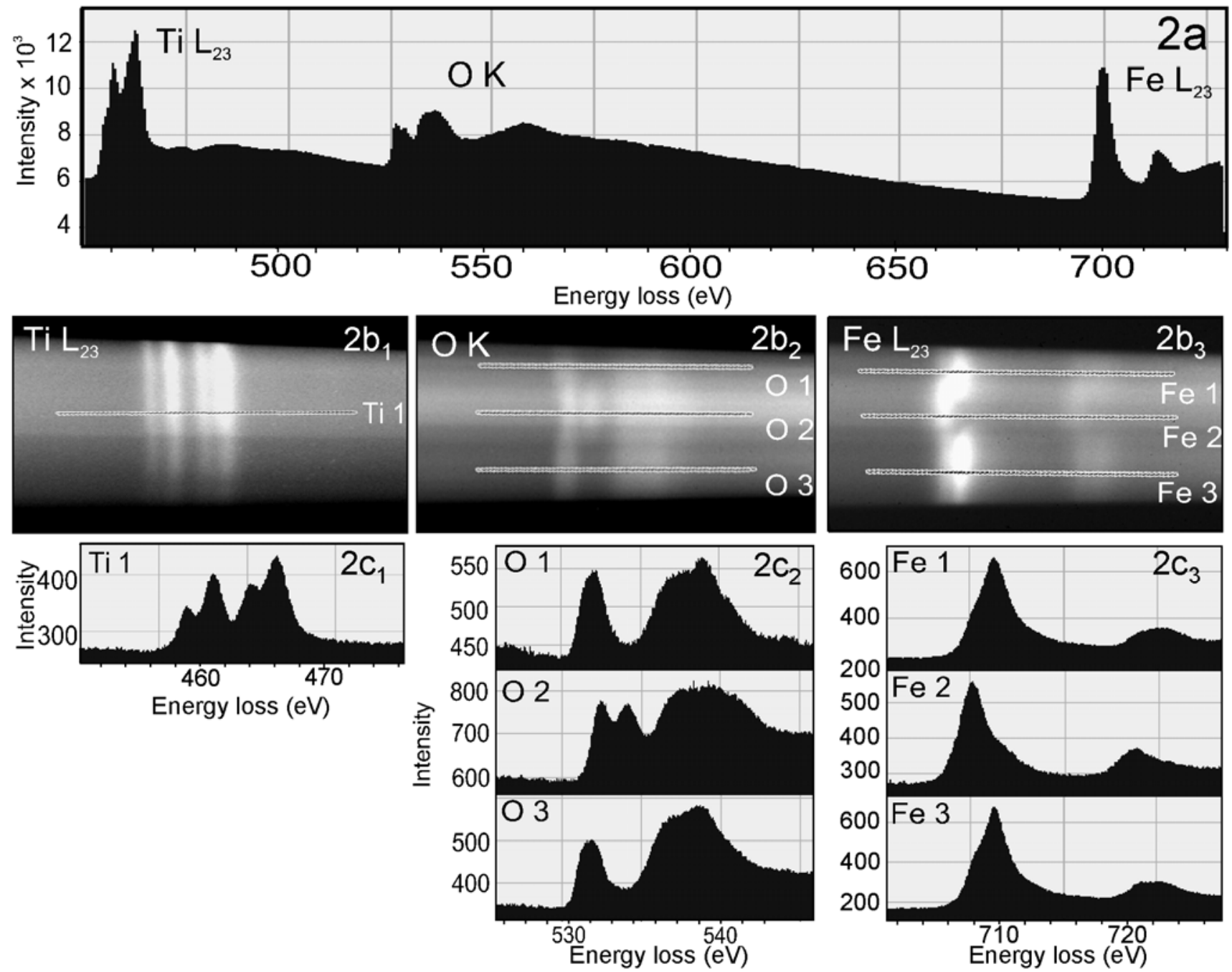

FIG. 2 a-c Spatially resolved EELS analysis of the exsolution lamella. a EELS of the element characteristic area, two dimensional spectrum images of $\mathbf{b}_{1} \mathrm{Ti} \mathrm{L}_{23}, \mathbf{b}_{2} \mathrm{O} \mathrm{K}$ and $\mathbf{b}_{3} \mathrm{Fe} \mathrm{L}_{23}$ and corresponding EELS spectra showing characteristic energy shift and ELNES structures $\mathbf{c}_{\mathbf{1 - 3} .}$. 